
\title{
Research Square \\ Research on Active Dustproof of Coal Handling \\ System
}

\section{Man Yi Zhou ( $\square$ zmy_web@163.com )}

Northwest Electric Power Design Institute Co., Ltd., Xi'an囚710075, China

\section{Original Article}

Keywords: Coal handling system of thermal power plant, Active dustproof, Coal dust pollution, Control of coal dust

Posted Date: January 23rd, 2021

DOl: https://doi.org/10.21203/rs.3.rs-151159/v1

License: (9) This work is licensed under a Creative Commons Attribution 4.0 International License. Read Full License 
4 Abstract: Coal handling system of Power plant(CHP) is easy to produce dust, which is the most

5 serious place of coal dust pollution in thermal power plant. With the gradual improvement of

6 national environmental protection requirements, the control of coal dust becomes more and more

7 important. The author believes that we should not wait for the pollution caused by coal dust to be

8 treated, but should take the initiative to attack, and should take the initiative to prevent dust,

9 starting from the source of coal transportation. In the process of designing coal conveying of

10 thermal power plant for many years, the author has carried out on-site investigation on many coal

11 handling systems, summarized experience and obtained relevant data. Through further analysis,

12 the main causes of coal dust are mastered, and the relevant measures of active dust control are put

13 forward from the technical point of view, in order to provide help for the comprehensive control of 14 coal dust in power industry.

15 Keywords: Coal handling system of thermal power plant; Active dustproof; Coal dust pollution;

16 Control of coal dust 
Coal is a major source of India's energy supply having the lowest energy cost

3 among the different fossil fuels accounting for $45 \%$ of the total energy mix and $60 \%$

4 of the installed electricity capacity. Future prediction indicates that coal is likely to

5 remain one of the primary energy sources for a long time in energy production. [1]

6 The coal handling system is prone to dust, which is the most serious place for coal

7 dust pollution in thermal power plant. In industries using bulk quantities of materials,

8 it is often necessary to store very large amounts of particulate materials. Any such

9 storage and the associated materials handling is likely to present dust problems.[2]

10 With the improvement of environmental protection requirements, the active dust

11 prevention is the highlight of CHP.

12 In the traditional design, the domestic and international coal dust control work is

13 mainly based on dust removal. When it comes to coal dust control, people's first

14 reaction is to set up a dust collector. This paper believes that the focus of coal dust

15 control work should be to prevent coal dust from dusting from the perspective of

16 process facilities. It should be based on active dust prevention, not dust removal after 17 dusting.

18 The author has summarized many years of work experience, conducted 19 on-the-spot investigations on multiple coal handling systems, collected a large amount 20 of data, analyzed the basic principles of various types of equipment and facilities in 21 the coal handling system, and summarized the different coal handling facilities and 
1 different coal handling, some methods of active dust protection.

21 Analysis of coal dust pollution factors

$3 \quad 1.1$ Pollution factor

4 Coal is transported into the entire process of the power plant. Through various

5 types of coal handling facilities or equipment, the process of dumping, transporting,

6 transporting and treating coal combustion increases the dusting intensity of coal. It is

7 well known that dust production is related to every mining activity, for every

8 operation dust generation is associated.[3] The dusting airflow causes the coal dust to

9 rise, and the local air is dusted to form a dust source. The air around these dust

10 sources is induced and disturbed, and the dust airflow is further spread, spread, and

11 flooded to the entire working place. The dust will be suspended in the air for a long

12 time and cannot be settled. The emission depends on different parameters related to

13 the specific activity or to the characteristics of the material, e.g.: particle size

14 distribution, coal type, moisture content, pile configuration, dumping height, as well

15 as on weather related parameters, e.g.: wind speed, relative humidity etc. [4]

16 After conducting investigations on coal handling systems of several thermal

17 power plants, it was found that coal dust pollution is likely to occur mainly in the

18 following four major aspects:

19 a. Coal quality factors such as small particle size, small surface moisture, large

20 volatile coal, easy to cause pollution;

21 b. When the coal is dumped and piled up in an open place, it is easy to have coal 
dust flying pollution;

c. When transporting the reloading equipment, it is easy to have coal leakage and

3 coal pollution;

4 d. On the rotating or vibrating equipment, it is easy to have powder leakage and

5 dust pollution.

$6 \quad 1.2$ On-site investigation of dustproof measures

7 During the investigation, it was found that each thermal power plant made the

8 following measures from the perspective of active dust prevention:

9 a. The raw coal is sprayed with water to suppress dust and humidify, and the coal

10 dust is basically controlled;

11 b. The dumper bucket, the car unloading ditch, the silo, etc. all considers the

12 amount of coal at the bottom of the coal bucket;

13 c. The coal supply equipment in the lower part of the silo adopts a fully sealed

14 structure to prevent dust;

15 d. The conveyor adopts anti-deviation measures;

16 e. The guide trough adopts a sealed guide trough;

17 f. The head funnel uses a two-stage alloy cleaner;

18 g. The Plough discharger is provided with a lock air baffle;

19 h. Minimize crossover in the system and compress the length of the coal chute;

20 i. Adopting the curve falling coal chute collecting and dust suppression

21 technology in the transfer station; 
j. Use a fully enclosed guide groove at the end of the conveyor.

k. Hydraulic cleaning is used in the coal transfer system, transfer station, coal

3 crusher building, trestle, coal trench, drive unit building and coal bunker;

m. Sprinkler facilities are installed around the coal yard to regularly spray water

on the coal pile to prevent coal dust from polluting the surrounding environment; from the above listed parties, and propose active and effective dust prevention measures from the aspect of coal.

92 Active dustproof in terms of coal quality

2.1 Coal dust pollution caused by coal quality factors

11 Coal is the world's most abundant and widely distributed fossil fuel and possibly

12 the least understood in terms of its importance to the world economy. [5] According to volatiles of coals, types of coals mostly used are lignite (US-United

14 States and FSU-Former Soviet Union), subbituminous coal (China, FSU, Australia 15 and Germany) and bituminous coals (China, US and FSU)[6]. Coal in thermal power 16 plant is mostly high-volatility bituminous coal and lignite. Coal with higher volatility 17 is more likely to produce coal dust. The list of anthracite, bituminous coal and lignite 18 is shown in Table 1:

\begin{tabular}{cc} 
Classification & Volatile $\mathrm{V}_{\mathrm{daf}} / \%$ \\
\hline Subbituminous coal & $\leq 10.0$
\end{tabular}


Bituminous coal $\quad>10.0, \&<37.0$

Lignite coal $>37.0^{\mathrm{a}}$

1 According to the analysis of the dust emission mechanism of coal dust, under the

2 same conditions of wind speed $10 \mathrm{~m} / \mathrm{s}$, the surface moisture of a thermal power plant

3 was tested. If the surface moisture of coal is $3 \%$, the dust emission is about below

$4 \quad 2.75 \mathrm{~g} / \mathrm{s} . \mathrm{m}^{2}$; if the surface moisture of coal is $6 \%$ to $7 \%$, the amount of dust is about 1

$5 \mathrm{~g} / \mathrm{s} . \mathrm{m}^{2}$ or less; if the surface moisture of coal is $10 \%$, the amount of dust is about 0.25

$6 \mathrm{~g} / \mathrm{s} . \mathrm{m}^{2}$. When the surface moisture of coal is reduced from $10 \%$ to $3 \%$, the amount of

7 dust increases by about 11 times, which indicates that the dry state of coal has a huge

8 impact on dust. In the utilization of coal, coal with high moisture content is difficult to

9 break; it also affects stability and heat conduction in boiler combustion. Therefore,

10 thermal power plant need to control the moisture of coal as much as possible, but it is

11 easy to dust when the water is low.

12 According to the actual measurement on the spot, when the small particle coal is

13 in the state of about $5 \%$ to $8 \%$ of water on the surface, the hand is caught in a group,

14 the hand is loosely opened, and it is not easy to dust; when the surface moisture is less

15 than $5 \%$, it is easy to fly with the wind. Easy to dust; when the surface moisture is

16 more than $8 \%$, fine coal is easy to bond and easy to block coal. As shown in table 2.

Table 2 The relationship between surface moisture and dust level

\begin{tabular}{ll}
\hline Surface moisture $(\mathrm{Ms})$ & Parameter \\
\hline $\mathrm{Ms}<5 \%$ & easy to dust, not easy to stop coal
\end{tabular}




$$
\begin{array}{ll}
5 \%<\mathrm{Ms}<8 \% & \text { not easy to dust } \\
\mathrm{Ms}>8 \% & \text { not easy to dust, easy to block coal }
\end{array}
$$

1 The volatile matter, particle size and surface moisture of coal types play a

2 decisive role in dust pollution. In general, the coal types of power plants are

3 determined by the market. We cannot change the volatile content and particle size of

4 coal, but we can adjust the surface moisture according to the actual situation to

5 achieve the effect of actively preventing dusting.

$6 \quad 2.2$ Coal quality factors active dustproof measures

7 Controlling the surface moisture of the coal to be in the range of about $5 \%$ to $8 \%$

8 is beneficial for effective dust prevention. When the surface moisture of coal

9 combustion is more than $8 \%$, it should be aired to reduce the surface moisture; when

10 the coal outside water is less than $5 \%$, humidification should be carried out to increase

11 the surface moisture. In most cases, the surface moisture of the coal entering the plant

12 is less than $5 \%$.

13 Coal-fired humidification is to spray and humidify the coal with lower external

14 water, so as to effectively improve the surface moisture and achieve dustproof effect.

15 The humidification operation can be carried out at the source of the thermal power

16 plant, such as a device for spraying and humidifying the coal burning in a dumper

17 room, a coal unloading ditch, a coal yard, a starting point of the first-stage Conveyor,

18 and the like. The following points need to be done:

19 a. Grasp the humidity and particle size of the coal, analyze whether it is 
1 necessary to spray humidification, and determine the number and flow rate of the

2 spray nozzle opening.

b. Master the stacking position, stacking time and stacking period of different coal in the coal yard, and humidify at the appropriate position when taking coal from

5 the coal yard.

c. Master the coal quality data such as moisture and particle size of the coal

7 surface stored in the coal yard, and covers the surface of the coal pile with a thin layer

8 of water film by spraying. Some adhesives can be added to the spray water to ensure

9 the coal humidity, self-ignition and dustproof.

d. According to the surface moisture condition of the coal stored in the coal or

11 coal yard, the spray humidification system can be set up along the whole process of

12 the coal handling system in the plant. The spray humidification is carried out in the

13 process of coal transportation. The amount of humidified water must be both

14 dust-proof and avoid adverse effects on system and boiler efficiency.

153 Outdoor active dustproof

$16 \quad 3.1$ Outdoor coal dust pollution

When unloading coal in the dumper room, coal unloading ditch and coal yard

18 area, the coal is thrown away from the height to do free fall movement, and the small

19 particles generated by the natural collision of the coal pieces collide with each other to

20 generate coal dust. During the continuous falling of coal, the static pressure of the

21 airflow in the dumper chamber coal hopper, unloading coal hopper and coal yard coal 
1 pile is reduced in the vertical direction and turbulence is generated, and the rising air

2 mass around the falling coal pillar continues to increase and Expansion, driving the

3 movement of fine particles of coal dust in coal. When the coal unloading operation is

4 temporarily paused, the coal dust is vertically rushed from the coal falling point. The

5 coal dust spurt out of the coal unloading area and then spread further. The drifting will

6 fall after a certain period of time. The larger coal particles will settle slightly faster,

7 but the smaller coal dust will be suspended in the air for a long time. If there is a wind

8 passing through the outdoor, the coal dust will be diffused. It extends to the dumper

9 room, the outside of the unloading ditch and the wider area around the coal yard. This

10 has caused coal dust pollution in the open space of the coal handling system of the

11 thermal power plant. The airflow around the falling coal is shown in Figure 1.

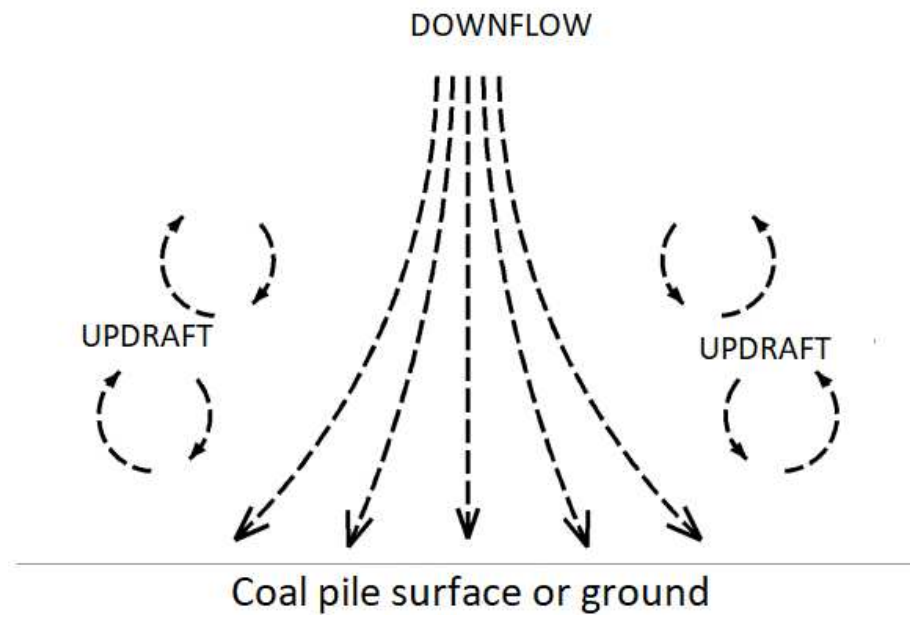

Fig.1 Airflow around falling Coal

The rate of coal dust falling is affected by coal dust particle size, ambient temperature, air humidity and other aspects. Generally, the pollution range is relatively large.

When the dumper unloads coal, when the dumper is tilted to about $95^{\circ}$, dust 
1 starts to overflow from the coal unloading side of the dumper. When it is tilted to

$2160^{\circ} \sim 165^{\circ}$, the dust reaches the maximum value, and the whole process takes about 2

3 minutes.

4 When unloading coal on the coal unloading ditch, dust will be; when the car is

5 completely lifted, the coal flow rapidly flows to the coal unloading ditch, and the coal

6 dust pollution is the most serious. The entire process takes about 1.5 to 2 minutes.

7 In the coal yard area, the operation methods such as bucket coal, coal unloading,

8 and coal-pulverizing coal yard will lead to continuous dust. Under the influence of the

9 wind, the scope of pollution will expand.

$10 \quad 3.2$ Outdoor active dustproof measures

11 According to the above analysis of the characteristics of outdoor dust, combined

12 with the experience of previous engineering, the most effective way is to seal the

13 outdoor during the engineering design, and cooperate with the water spray to prevent

14 dust.

$15 \quad 3.2 .1$ Sealed active dustproof

16 Sealing the whole dumper room or coal unloading ditch, setting up the electric

17 closing door in the position of pulling the coal train car into or out of the dumper

18 room or unloading the coal ditch, and interlocking with the opening and closing of the

19 unloading system to prevent coal dust Out of the way. It is also possible to provide a

20 sealing device for the body of the dumper to be closed, which can effectively reduce

21 the confined space and control the dust within a minimum range. 
After the building or equipment is sealed, a suction device can be arranged under

2 the hopper, a negative pressure is generated at the coal hopper, the rising air mass

3 generated during the discharge is effectively eliminated, and a water spray device is

4 arranged at the discharge port of the coal hopper. Seal the coal dust in the coal hopper.

5 Coal yard, as one of the most important links of coal storage in fossil fired power

6 plant, its economy effect, security and environmental friendliness has drawn

7 worldwide attention.[7] Compared to open air coal yard, the enclosed coal yard has

8 the advantage of higher land use rate as well as better outdoor air condition.[8]

9 Ventilation, one of the crucial methods to improve indoor environment in coal yard,

10 helps to improve indoor thermal condition and decrease the combustible

11 concentration.[9] The whole coal yard is sealed. The strip-shaped closed coal shed

12 and round closed coal shed are commonly used in the project to ensure that the

13 surrounding environment of the coal yard is not polluted by coal dust, and a dust

14 suppression device is installed inside the closed coal shed.

$15 \quad 3.2 .2$ Water spray active dustproof

16 It has been recognized that such conventional approach provides an estimation

17 result with a substantial margin of error which could affect the effectiveness and

18 performance of the dust removal system.[10] In a more realistic viewpoint, foot-print

19 area of water spray, which can be estimated by the trajectory of the droplets on the

20 periphery of the water spray, would also affect the removal efficiency.[11] In addition,

21 the overall efficiency of spray nozzles should be estimated by taking into account the 
1 ambient condition, such as wind velocity and concentration of fugitive dust in the

2 ambient air, as well as the generation of fugitive dust by the apparatus of interest. [12]

3 A water spray device is arranged at the position of the dumper and the unloading

4 ditch, and is interlocked with the unloading device. The sprinkler is arranged

5 three-dimensionally in the dust-prone position in the coal unloading device, and the

6 nozzles are arranged in the unloading direction. The nozzle spacing can be arranged

7 according to the spacing of $300 \sim 500 \mathrm{~mm}$. The number of nozzles and the amount of

8 water spray can be adjusted according to the different coal quality.

9 A water spray device is arranged in the closed coal shed, arranged around the

10 coal yard and on both sides of the turbine track base, and the spacing should be

11 considered to be less than 30 meters. It is also possible to provide a spray dustproof

12 device at the wheel hopper on the bucket machine equipment, and to interlock with

13 the bucket turbine from the start and stop.

14 The water spray device uses industrial water, and generally sprays and

15 humidifies coal pile twice a day for half an hour. The water sprayed on the surface of

16 the coal pile is volatilized faster, especially in dry weather. It is considered to add the

17 dust suppressant to the spray water, a dust suppressant by applying a blend of mixed

18 polyethylene oxide (g-PEO) and sodium dodecyl sulfate (SDS), The g-PEO\&SDS

19 solution, utilizing SDS converted the hydrophobic coal surface to a hydrophilic area

20 by the adsorption of the surfactant molecule exclusively at hydrophobic sites and

21 g-PEO linked closely with the coal dust to form a layer of gel film on the surface of 
1 the coal dust after air-drying, possessed the optimal performance for coal dust control

2 and did not affect the use of the coal.[13]

34 Carrier equipment active dustproof

4 The carrier equipment of the CHP mainly includes belt Conveyor, coal chutes

5 and guide troughs.

$6 \quad 4.1$ Carrier equipment dust pollution

$7 \quad$ 4.1.1 Conveyor dust pollution

8 Conveyors emit dust from four points: (1) the tail end, where the material is

9 received (due to splash and sometimes also due to an air induction depending on the

10 manner of material delivery); (2) the conveyor skirting; (3) the return idlers (due to

11 carry-back of fine dust on the return belt); and (4) the head end, where material is

12 discharged to a chute or the equipment succeeding it.[14]

13 Normally, the belt is respectively supported by the idlers. During the operation,

14 under the action of the driving force, rolling friction is formed between the belt and

15 the idler idler, so that the belt runs forward along the length direction of the Conveyor.

16 Due to factors such as equipment manufacturing, construction, installation, etc., the

17 force of the belt during operation is uneven, and the upper belt surface may be

18 deflected. It is easy to spill coal from out the belt surface.

19 a) Belt deviation cause spill coal

20 The center line of the idler is not perpendicular to the running direction of the

21 belt, and is at an angle of $90^{\circ} \pm \theta$, as shown in Figure 2. Then, the belt will be shifted 
1 to a direction larger than the right angle side. This is because the surface of the idler

2 and the belt are in contact with each other, and the circumferential rotation direction

3 of the idler is at an angle of $\theta$ with the linear running direction of the tape, and the

4 final running direction is met. In the vector synthesis relationship, the friction between

5 the idler and the belt pushes the belt to one side to form a deviation.

6

9 vertical direction or the blanking point is not at the center of the Conveyor, showing

10 the eccentricity of the blanking point, as shown in Figure 3, the Conveyor will be

11 transported. The belt increases the thrust on one side, causing the belt to deflect to one 12 side. blanking point, the center line of the longitudinal direction of the Conveyor cannot be 17 guaranteed to be in a straight line, but is in a state of bending the center line, so that 
1 the heights on both sides of the belt are inconsistent. As shown in Figure 4. The belt

2 will be deviated.

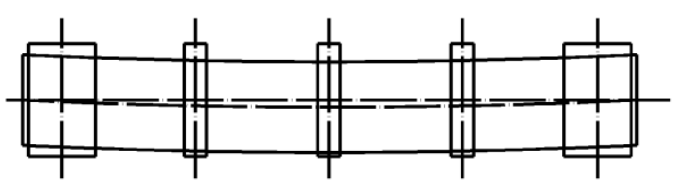

Fig.4 Bending centerline

b. Belt fluctuations cause coal to be sprinkled.

In general, the upper idlers are arranged at intervals of $1200 \mathrm{~mm}$. Due to the insufficient rigidity of the belt and the excessive weight of the transport coal, the belt will be recessed downward at the position without the idler, as shown in Fig. 5. Coals will fluctuate up and down with the advancement of the belt, causing small particles of coal dust to bounce off the surface of the belt, and then causing pollution.

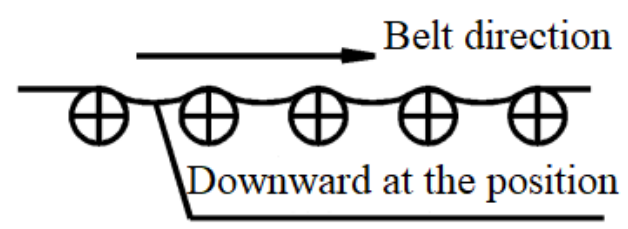

Fig.5 The belt is in a subsidence state

c. The belt is not clean causes pollution automatically cleaning the sticky coal adhered to the surface of belt. Pollution is caused by the difficulty in completely cleaning the coal at the vulcanized joint of the belt.

d. The conveyor running wind speed causes pollution

9 During the operation, due to the high-speed operation of the Conveyor, the coals 
1 on the belt and the static air around the equipment form a relative movement speed,

2 and the relative movement wind speed causes the coals external water moving on the

3 upper conveyor belt to evaporate rapidly. The fine particles of coal dust on the surface

4 are diffused and dispersed into the internal space of the trestle to pollute the

5 environment.

\section{$6 \quad$ 4.1.2 Coal chute dust pollution}

The chute and the buffer locker, that is, the coal drop pipe, are used from the lower

8 flange of the head Conveyor to the upper flange of the lower feed Conveyor. The falling

9 coal chute is conventionally designed as a shape of rectangular section, and the falling coal

10 chute are connected by flange bolts, and sealed by a sealing material such as a graphite

11 gasket or a rubber gasket. The inner coal flow flushing surface of the falling coal chute is

12 provided with wear-resistant lining, the lining material is usually cast iron lining or ceramic

13 lining, and the lining is connected with the wall of the falling coal chute by bolts.

14 After long-term use of the coal chute, it may cause the chute wall to wear through the

15 holes, wear-resistant lining wear and fall, and the flange connection of the falling coal chute

16 is not tight. When the coal is dropped inside the blanking chute, the initial velocity is large,

17 and a strong induced wind is generated, which causes dust to overflow in the above holes or 18 gaps.

19 After analyzing the phenomenon of coal dust pollution at the coal chute, the main 20 reasons are as follows:

21 a. The connection flange is not tightly sealed; 
b. The conventionally designed head funnel cannot meet the requirements of the angle

2 of coal entering the Conveyor with different inclination angles and different speeds. The

3 coal flow is violently impacted at the head funnel, which aggravates the dust phenomenon

4 of coal powder;

c. The conventionally designed coal chute has too many hard folds, and the impact and collision between the materials at the break point occur, and the dust air mass expands; coal chute, and the wind speed can reach about $10 \mathrm{~m} / \mathrm{s}$. High wind speed drives a large amount of dust to be ejected from a tightly closed place;

e. Arrange the coal chute vertically, when the height difference is more than 5 meters,

11 the coal will fall quickly, and the gravity will easily damage the guide trough and the overflow apron at the lower tribe point, causing gaps between the equipment to cause coal 13 overflow.

14 4.1.3 Guide trough coal dust pollution The guide trough is installed at the end of the conveyor, and its function is to prevent

16 the coal falling from the coal chute from being scattered, and the coal can be rapidly 17 accumulated in the center of the belt tape on the conveyor to form a stable shape. The guide 18 trough should have sufficient height and section. The design of the guide trough structure 19 mainly includes the section type, length, and sealing form. The traditional guide trough is a 20 type with a curved top, which increases the internal volume of the guide trough, which is 21 beneficial to reduce the induced wind pressure and is equipped with a dust-proof curtain at 
1 the exit. The periphery of the guide trough should be able to automatically adjust the

2 corresponding sealing pressure with the change of internal airflow pressure to ensure good

3 air tightness, so that the inside of the guide trough is completely isolated from the outside,

4 and the effect of exhausting dust is ensured.

5 In actual use, the wear of the guide trough itself is very serious, resulting in serious

6 dusting and powder leakage and pollution. The main reason is that the traditional guide

7 trough and the belt are closed with a rubber skirt, and the sealing effect is poor. When the

8 conveyor is in operation, the coal piece flowing down from the coal chute will exert a large

9 impact force on the belt in the guiding trough under the action of gravity, causing elastic

10 vibration of the belt, resulting in rubber skirt and belt. There is a gap between them, and the

11 small coals are ejected from there. Since the entire length of the guide trough is about 10

12 meters, there are many gaps, so there are many powder leakage points in the lower part of

13 the guide trough.

14 The lack of tight sealing between the guide trough and the belt is the root cause of

15 powder spraying around the guide trough. The "large drop in the coal chute" and the "small

16 volume of the guiding trough" are the main causes of the external jetting of coal powder at

17 the guiding trough. When the coal falls into the guide trough from above, the vertical drop

18 is about 5 to 10 meters. When the coal flow drop exceeds 4 meters, it is difficult to suppress

19 the large amount of dust generated by the high-speed coal flow under the induced wind by

20 using the conventionally designed guide groove. The larger the drop, the faster the coal

21 flow undershooting speed, and the greater the positive pressure induced wind formed in the 
1 coal chute when falling. The surrounding of the guide trough is not tightly sealed. Under the

2 action of positive pressure induced wind, the coal powder is sprayed from the joint gap of

3 the guide trough, the gap between the guide trough and the belt, and the front and rear ports

4 of the guide trough.

$5 \quad 4.2$ Active dustproof measures for carrying equipment

$6 \quad$ 4.2.1 Conveyor active dustproof

7 For the various coal dust pollution situations of conveyor equipment, the 8 following solutions are proposed.

$9 \quad$ 4.2.1.1 Prevent the conveyor from moving strongly

10 The direction of the synthetic external force received by the belt is inconsistent

11 with the running direction, which is the root cause of the deviation of the belt.

12 Therefore, it is necessary to improve the design, manufacture, installation,

13 commissioning, use and maintenance of the conveyor. The method of adjusting the

14 deviation of the belt can be summarized as the following.

a. Adjust the idlers, tensioning mechanisms and other components. Correct the

16 rear end of the head to the center of the drum to eliminate the deviation between the

17 direction of the belt and the direction of travel.

b. Reasonably install the centering idler and the limit idler to force the belt to

19 reset when the deviation is reversed.

c. Adjust the position of the blanking point, and set the coal flow regulating

21 baffle or the coal flow buffering drum in the coal chute so that the coal flow is at the 
center of the belt when it falls.

d. On the conveyor, install the array automatic correcting device according to the actual length to prevent the belt from running off.

e. Do a good job of management, immediately remove the adhesive tape on the belt; do the vulcanization of the belt joint position to ensure the joint is smooth.

\subsubsection{Prevent Conveyor from fluctuating}

To control the belt surface fluctuation, it is necessary to strictly control the design, manufacture and installation. According to the use requirements, the running speed of the conveyor should be reduced as much as possible, the spacing of the idlers should be arranged reasonably, and the selection and delivery volume of the belt should be strictly controlled. Adjust the idler with a large beating range.

\subsubsection{Reasonable setting of the cleaner}

The cleaning effect of the conveyor cleaner is directly related to the dust pollution situation. Therefore, the cleaning device should be regularly inspected and maintained: ensure the use of the head H-type cleaner, P-type cleaner, and empty-cleaner; ensure that the cleaner blade is in close contact with the belt; In the product selection, use a cleaner blade with constant pressure, small friction coefficient, good elasticity, wear resistance and good cleaning effect.

Install a coal recovery bin at the position of the sweeper in the return section of the belt, so that the cleared pulverized coal falls freely to the recovery bin to avoid secondary pollution and be cleaned regularly. 
3 bandwidth, belt speed and output configuration of the conveyor are detailed the

4 manual. Taking the more commonly used $\mathrm{B}=1400 \mathrm{~mm}$ conveyor as an example, the

5 minimum speed and maximum allowable selection values are $1.0 \mathrm{~m} / \mathrm{s}$ and $5.0 \mathrm{~m} / \mathrm{s}$,

6 respectively. It is recommended to use a moderate belt speed of $2.5 \mathrm{~m} / \mathrm{s}$ or $3.15 \mathrm{~m} / \mathrm{s}$,

7 which avoids the lose capacity caused by the choice of low belt speed, and avoids the

8 choice of high belt speed to cause coal dust to fly.

$9 \quad$ 4.2.1.5 Reasonably set humidification or spray device

A spray humidification device is provided on the inner side of the top of the

11 conveyor head cover, the position of the tail receiving point and before the outlet of

12 the guide groove, and the starting point of the return working face, and is interlocked

13 with the conveyor. The device can be used to spray the coal flow entering the coal

14 chute, the surface of the coal flow surface, and the returning belt to increase the water

15 content outside the coal, which can effectively reduce the dust pollution on the surface

16 and back the head, tail and the upper belt of the conveyor. The shape of the nozzle,

17 the angle of the nozzle, the number of nozzles, the amount of water sprayed, the water

18 pressure, and the control method can be reasonably configured according to the coal

19 quality of the project.

20 4.2.2 The coal chute actively dustproof

21 4.2.2.1 Equipment seal 
The equipment seal mainly includes between the head funnel and the coal chute,

2 between the coal chute and other coal chute, between the coal chute and the buffer air

3 locker, between the buffer air locker and the guide trough, and between the guide

4 trough and the belt.

If flange connection is used between the above equipment, a reliable gasket should be installed for sealing to avoid direct connection.

In the seal between the side of the guide trough and the belt, it is recommended to provide a flexible double-layer sealing material with good elasticity, high strength

9 and wear resistance. The inner layer sealing material mainly controls a large amount

10 of coal flow on the belt surface, and the outer layer sealing material leaks the coal

11 powder from the gap of the inner layer sealing material to be controlled between the

12 double-side sealing materials. To avoid belt is in a subsidence and forming a gap

13 between the sealing materials, a pallet can be placed between the idlers to lift the belt.

14 4.2.2.2 Head funnel series selection

15 Product serialization is an advanced form of standardization and a product of

16 high standardization. The existing head funnel selection manual for fixed bandwidth,

17 only one or two head funnels are available for selection, for different belt speeds and

18 tilt angles, the $\mathrm{F}$ and $\mathrm{E}$ values in the head funnel parameters (as shown in Figure 6) all

19 the same. At different coal burning rates, different speeds, and different tilt angles,

20 such standard designs clearly do not accommodate the lateral parabolic distance

21 requirements of coal burning into the head funnel. 
2 needs of use. It is necessary to make the basic selection parameters of the head funnel

3 as the comprehensive determination factor of the head funnel selection, such as the

4 bandwidth, belt speed, inclination angle and coal particle size. This can make the head

5 funnel suitable for the parabola requirements of all types of conveyor heads, so that

6 the coal flows smoothly and without impact into the head funnel and the lower tribe

7 coal chute, which can effectively eliminate the phenomenon of dust pollution impact

8 of coal flow and chute wall collision.

\section{4.2.2.3 Streamlined coal chute}

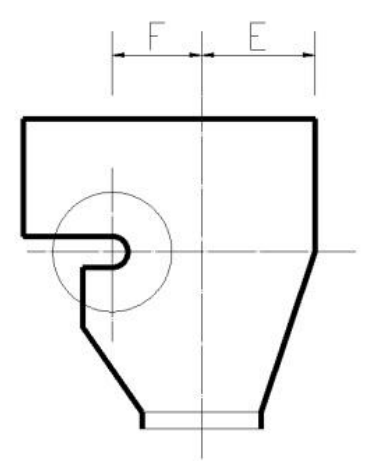

Fig.6 The head funnel of Conveyor

When the multi-segment linear traditional coal chute is connected another, the coal flow cannot flow close to the chute wall due to the large inflection point, causing the coal block to collide back and forth and generate a large amount of flying dust. The falling speed of the coal flow is getting faster and faster, increasing the induced air volume and aggravating the dust leakage.

For the shortage of traditional coal chute, we often use streamlined chute to make up for the shortage of traditional coal chute. The streamlined chute has the following 
1 advantages: according to the characteristics of the coal burning flow, the streamline

2 chute can be designed to regularize the coal flow inside the coal chute; avoid the

3 collision between the coal combustion to generate dust; and suppress the coal flow

4 falling process Acceleration in the middle, reduce the generation of induced wind;

5 ensure that the lower conveyor is centered and avoid the unevenness of the belt to

6 produce deviation; reduce the impact damage to the equipment; reduce noise. The

$7 \quad$ streamlined chute has these advantages and can well suppress the generation of coal

8 dust.

9 4.2.2.4 Reduce the blanking height difference

10 Reducing the drop in the transfer point is also an effective dust control measure.

11 In the design stage, by reducing the unnecessary arrangement of the coal chutes, the

12 drop of the transfer point should be reduced as much as possible, the falling distance

13 of the coal is reduced, and the falling time is shortened, which can effectively reduce

14 the impact speed of the coal flow drop.

$15 \quad$ 4.2.2.5 Buffer lock setting

16 The intact buffer air lock can reduce the induced wind by more than $90 \%$.

17 Therefore, the buffer air lock should be regularly maintained at regular intervals to

18 ensure flexible opening and closing of the air lock baffle, no wear on the side wall,

19 and tight connection.

20 According to the weight of the air lock baffle, adjust the weight of the weight

21 block, and regularly lubricate the bearing to ensure its stable operation; if the baffle or 
1 casing is found to be seriously worn, repair or replace it in time. If the buffer air lock

2 is not provided, the deflector should be installed at the blanking point of the coal

3 chute to avoid the side plate wear and reduce the impact of the coal flow on the side

4 of the belt, so as to avoid the irregularity of the falling point and prevent the deviation.

$5 \quad$ Reduce the possibility of contamination caused by coal leakage.

$6 \quad$ 4.2.2.6 Other measures

$7 \quad$ Regularly check and maintain the coal chute. The inspection content should at

8 least include the following contents: whether the wear-resistant lining plate and its

9 fixing bolts are worn out and leaked, and replace it; if the sealing material at the

10 connecting flange is damaged, the powder leakage is caused, and the glass glue is

11 used Or other fillers for sealing treatment; if the wear-resistant lining is not installed,

12 the wall of the coal chute is worn, and the wear-resistant lining is installed in time.

13 The liner can be made of medium chromium alloy material, such as Medium

14 chromium alloy material.

$15 \quad$ 4.2.3 Guide trough active dustproof

$16 \quad$ 4.2.3.1 Ensure that the joints are sealed

17 Avoid dust leakage from the joints of the guide trough, check whether there is a

18 powder leakage point and seal it: seal the joint surface of the guide trough with

19 sealing material; seal the side plate with filler such as sealant; use high strength The

20 material with low friction resistance (such as: Polyethylene board) is made into the

21 pallet, replacing the idlers on both sides of the groove to form a continuous closed 
1 coal conveying passage; using double-layer anti-overflow skirt and conveying The

2 labyrinth seal is formed at the joint to prevent dust from leaking. The double-layer

3 anti-overflow skirt material can be made of polyurethane composite material.

4 4.2.3.2 Determine a reasonable cross-sectional area internal pressure, the speed of coal-fired dust inside the guide trough will also

21 gradually decrease, and then naturally settle, effectively reducing the external spray of 
coal powder.

The formula for the length of the guide groove is

$\mathrm{L}=\mathrm{f}(\mathrm{Q}, \mathrm{B}, \mathrm{H}, \mathrm{V}, \mathrm{D}$

Where: $\mathrm{L}$ is the length of the guide trough, $\mathrm{m}$; $\mathrm{Q}$ is the transport volume; $\mathrm{B}$ is the conveyor bandwidth, $\mathrm{m}$; $\mathrm{H}$ is the coal flow drop, $\mathrm{m}$; $\mathrm{V}$ is the coal flow drop speed, $\mathrm{m}$ / $\mathrm{s}$; D is the coal Particle size, $\mathrm{mm}$.

\subsubsection{Setting the dust curtain}

A two four stage labyrinth dust curtain is added inside the guide trough to make the coal dust inside the guide trough form a turbulent flow, which can slow the induced wind in the guide trough and reduce the dust caused by the impact friction inside the coal flow. The installation position of the curtain can be set at a position one meter away from the direction of the coal flow in the blanking point and one meter in front of the suction port of the dust collector.

\subsubsection{Blanking point arrangement buffer bed}

Conventional conveyor usually use cushioning idlers at the blanking point, and the belt surface will be wavy when the belt is heavily loaded, as shown in Fig. 5. This will create a gap between the belt and the guide trough.

Compared with the use of the buffer idler, the use of the buffer bed does not cause the belt to sink and the gap occurs to cause the powder to be sprayed outward, and also has the functions of buffering, vibration absorption and noise reduction.

\subsubsection{Installation of automatic water spray device}


An automatic water spray device is installed at the tail, middle and front of the

2 guide trough. The tail water spray device can block the coal dust from overflowing

3 from the tail; the middle water spray device can humidify the coal flow entering the

4 guide trough to make the external water meet the dustproof requirement; the front

5 water spray device can position the guide trough outlet the coal dust is enclosed inside

6 the guide trough.

$7 \quad 5$ Rotating vibration equipment active dustproof

$8 \quad 5.1$ Rotating vibration equipment coal dust pollution

9 The rotary or vibration equipment for generating dust mainly includes a coal

10 crusher, an impeller coal feeder, a sampling device, a plough discharger and the like.

11 5.1.1 Coal dust pollution from coal crusher When the coal crusher performs the crushing operation, the rotor part drives the

13 ring hammer and the ring arm to rotate at a high speed, and an induced wind is

14 generated. After the raw coal is crushed, blasting and carrying coal dust are generated

15 in the coal crusher chamber and the lower tribe coal hopper. When the coal is dropped

16 to the receiving point of the lower conveyor, the fine granular coal powder will be

17 tightly closed. A large amount of dust is sprayed outside, causing pollution in the

18 outer area of the crusher. In addition, vibration occurs when the equipment is running,

19 and coal dust that sinks on the floor surface will cause secondary flying dust pollution

20 due to vibration of the floor caused by equipment vibration.

$21 \quad$ 5.1.2 Impeller coal feeder dust pollution 
When the impeller coal feeder is engaged in the unloading of coal, the coal is

2 dumped from the exit of the unloading ditch to the receiving point of the lower

3 conveyor, and dust will fly during the falling process. As the impeller coal feeder

4 moves linearly, the diffusion range of the dust source points increases. At the same

5 time, there is also a phenomenon of sprinkling coal, which leads to more coal in the

6 moving path of the impeller coal feeder.

$7 \quad$ 5.1.3 Sampling device coal dust pollution

8 When the sampling device is working, when the sampling head scrapes the

9 moving coal flow, part of the coal is washed out of the belt surface and scattered to

10 the ground due to the collision, and the fine coal dust will fly to air to cause the coal

11 dust Pollution. In the recovery of residual coal, the free-falling coal flow and the

12 laterally moving coal seam flow will cause vertical collision, which will also cause

13 coal sprinkling and dust.

$14 \quad$ 5.1.4 Plough discharger coal dust pollution

15 When the plough discharger is working, when the coulter scrapes through the

16 moving coal flow, part of the coal flow is washed out of the belt and scattered to the

17 ground due to the collision, and the fine coal dust will fly to the air to cause coal. Dust

18 pollution.

19 The upper mouth of the conventional plough discharger lock air baffle funnel is

20 open structure, and the buffer pipe baffle is installed on the blank pipe section. When

21 the plough discharger is operated, it will be buffered by the gravity of the free fall of 
1 coal combustion. The air lock baffle is opened, and the removed parabolic flow of

2 coal flows into the funnel, causing turbulence, as shown in Figure 1. The ascending

3 air mass around the falling coal stream drives the fine particle coal dust in the coal to

4 make a rising motion, causing a large-scale pollution in the coal bunker layer.

$5 \quad 5.2$ Active dustproof measures for rotating vibration equipment

6 For this type of equipment, the main purpose is to seal, such as by adding rubber,

7 sealing the equipment interface, etc., and humidifying the coal to control dust.

$8 \quad 5.2 .1$ The coal crusher actively dustproof

9 A dust extraction system should be design and install to extract the airborne dust,

10 including respirable particles using a combination of misting and high efficiency

11 cyclone technologies.[15]

12 a. When selecting equipment, use equipment with small air volume to avoid the

13 problem of dust generated by blasting of coal crusher equipment.

14 b. Soft connection between the upper mouth of the equipment and the hopper,

15 the lower mouth and the lower part of the coal hopper, and the flange joint is strictly

16 sealed. Materials with good sealing properties, such as dust-free asbestos rope or wool

17 can be used. Equipment inspections and problem handling are also required on a 18 regular basis.

19 c. Setting the air volume adjusting device on the top of the main body of the coal 20 crusher to adjust the air volume of the inlet and the outlet, so that the coal inlet of the 21 coal crusher is slightly negative and the outlet is slightly positive pressure, so that the 
1 main pollution source is controlled in the internal space of the coal crusher equipment

2 body and will not pollute the outside of the coal crusher equipment.

3 d. The amplitude of the ring hammer does not match the design value due to the

4 installation quality or the maintenance of the equipment. The vibration of the ring

5 hammer is not balanced, which causes the vibration of the coal crusher to increase

6 during operation. It is necessary to periodically measure the amplitude of the coal

7 crusher at no load and heavy load. If the amplitude is greater than the requirements of

8 the equipment manufacturer, there is a possibility that the ring hammer will be

9 unbalanced. In addition, the ring hammer as a consumable part of the coal crusher

10 should be regularly inspected and replaced.

$11 \quad$ 5.2.2 The impeller coal feeder actively dustproof

12 When the impeller coal feeder is working, it needs to reciprocate, and the dust

13 generated during the dumping of coal is widely spread. Due to the mode of operation,

14 it is difficult to completely seal the impeller coal feeder equipment. This section gives

15 two dust protection measures.

16 a. Install the flat bag filter on the impeller coal feeder and install a sealed dust

17 cover on the upper part of the impeller. The dust-containing air is sucked into the flat

18 bag filter through the dust hood and then dropped onto the lower conveyor. A closed

19 guide groove is provided on the conveyor to prevent dust from overflowing.

20 b. Add a water spray dust suppression device on the body of the impeller coal

21 feeder, and interlock with the start and stop of the impeller coal feeder. In the range of 
1 impeller dumping and unloading coal, the water mist sprayed by the spray dust

2 suppression device forms a mist, and the coal dust is wrapped inside the water mist

3 group, so that the flying coal dust can be quickly combined with the water mist and

4 landed in the lower conveyor on board.

$5 \quad$ 5.2.3 The sampling device is actively dustproof

$6 \quad$ For the phenomenon that the sampling head collides with the coal flow so that

7 part of the coal particles are washed out of the belt, a rubber baffle or a sealing cover

8 of appropriate height can be set at the collision site on both sides of the conveyor, so

9 that the coal flow collision sampling The coal particles that bounced behind the head

10 returned to the belt again.

$11 \quad$ 5.2.4 Plough discharger active dustproof

12 For the phenomenon that the plough discharger coulter collides with the coal

13 flow so that part of the coal particles are washed out of the belt, a rubber baffle or a

14 sealing cover of appropriate height can be arranged on both sides of the conveyor at

15 the collision site to make the coal The coal particles that bounced after the flow

16 collided with the coulter returned to the belt again.

17 The upper opening of the conventional plough discharger funnel is open

18 structure, so the upper part of the plough discharger lock air baffle can be sealed, a

19 sealing top cover is arranged on the top and the top of the upper mouth, and the coal

20 flow enters the funnel. A dust curtain is provided at the side of the mouth.

21 A water spray dustproof device is placed on the top of the funnel. The device is 
1 used to spray the coal stream entering the funnel, which can effectively control the

2 coal dust pollution there. The shape of the nozzle, the angle of the nozzle, the number

3 of nozzles, the amount of water sprayed, the water pressure, and the control method

4 can be reasonably configured according to the engineering conditions. We can use arc

5 jet nozzles, the results of field experiments show that the total dust and respirable dust

6 suppression efficiency of arc jet nozzles is $85.8 \%$ and $82.6 \%$ respectively, which are

$7 \quad 1.39$ and 1.37 times higher than the full cone nozzles and 1.20 and 1.19 times higher

8 than the flat nozzles.[16]

96 Hydraulic cleaning active dustproof

$10 \quad 6.1$ The necessity and function of hydraulic cleaning

11 After the equipment of CHP is shut down, the dust in all the building space of

12 the coal conveying system will gradually settle to the ground or the surface of the

13 equipment. When the coal handling equipment is started again, it will cause secondary

14 flying pollution of the dust on site. Therefore, it is necessary to set up water cleaning

15 in CHP to treat this part of the dust.

16 The hydraulic cleaning plan refers to the installation of the flushing mother pipe

17 and the flushing reel in all the building (structure) of the coal conveying system: the

18 dumper room, the unloading coal ditch, the trestle, the transfer station, the coal

19 crusher room, the coal bunker, etc. box. A set of flushing reel boxes is arranged at

20 intervals of $15 \sim 20 \mathrm{~m}$. Rinse the reel drum flushing tube length is about $15 \sim 20 \mathrm{~m}$.

21 Hydraulic cleaning can clean this part of the dust, and it can also maintain a certain 
1 humidity on the ground of the building (structure) to avoid secondary pollution caused

2 by external dust and other factors.

3 In order to do a good job of hydraulic cleaning, it is necessary to improve the

4 relevant coal-concrete structure, such as the anti-leakage treatment plan for the slab

5 and the trestle, the water-passing measures at the interface of the trestle and the

6 transfer station, and the protection edges around the floor cavity. The water retaining

7 raft setting scheme, the adjustment scheme of the ground drainage slope, the dredging

8 scheme of the drainage channel, and the waterproof treatment scheme of the wall

9 surface, as so tiling or water resistant paint.

10 In addition, recycling of flushing water is required.

$11 \quad 6.2$ Calculation of water supply in water cleaning

12 Hydraulic cleaning hour water supply calculation formula is

$13 \quad \mathrm{Gx}=\mathrm{gx} * \mathrm{a} / \mathrm{t}$

14 The formula for calculating the daily water supply for hydraulic cleaning is

$15 \quad \mathrm{Gr}=\mathrm{m}^{*} \mathrm{gx} * \mathrm{a}$

16 Where: Gx is the water supply per hour, $\mathrm{m}^{3} / \mathrm{h}$; $\mathrm{gx}$ is the amount of flushing water

17 per unit area (recommended value 0.01$), \mathrm{m}^{3} / \mathrm{m}^{2}$; a is the area where hydraulic flushing

18 should be performed, $\mathrm{m}^{2} ; \mathrm{t}$ is the time of each flushing (Recommended value 0.5 to 1 ),

$19 \mathrm{~h}$; Gr is the daily water supply, $\mathrm{m}^{3} / \mathrm{d} ; \mathrm{m}$ is the number of daily ground flushes.

20 The $\mathrm{m}$ value needs to be determined according to the water content of the coal,

21 the transportation method, the local meteorological conditions, the water supply 
1 conditions, etc., and is generally taken once to three times.

Hydraulic cleaning should be carried out in an organized manner according to

3 the slope of the building. The water should not be too concentrated. The maximum

4 water consumption per hour of the whole coal handling system should not exceed

$5150 \mathrm{~m}^{3} / \mathrm{h}$.

67 Conclusion

The market due to increasing extraction of shale gas and low natural gas prices

8 puts the gas power plants in favor and poses increasing pressure on closing some coal

9 fired plants[17]. Therefore, if existing power plants want to continue to be retained, it

10 is very important to meet environmental requirements.

11 The dust control of CHP of a thermal power plant is a comprehensive treatment

12 process. If the problem is considered only from the aspect of setting up a large dust

13 collector in the system, it cannot achieve a good governance effect. The cause of dust

14 generation should be carefully studied, and the problem should be solved from the

15 root causes of all equipment of CHP, and the dust pollution of CHP should be

16 eliminated in the bud.

17 This paper only discusses some of the main measures for active dust control of

18 CHP process equipment, in order to provide reference for comprehensive treatment of

19 dust in coal handling system. For the comprehensive control of dust in CHP, the

20 principle of root-treating should be adopted, and the project should be artificially

21 enlarged to avoid waste of engineering investment. 
References

2 [1] Dibyajyoti Behera, Barun Bumar Nandi, Sumantra Bhattacharya. 2020. Studies on

3 Combustion Characteristics of Density by Density Analyzed Coal, Journal of Energy Resources

4 Technology, 012301/ Vol. 142, JANUARY 2020.

[2] Warren Spring Laboratory: Dust and Materials Handling: Report No.2-Dust Generation in

Materials Handling, by P.G. Murfitt and C. Schofield.Stevenge, UK: Warren Spring Laboratory, 1981.

8 [3] Kumar Prashant, Padhi Aswini Kumar. 2016. Assessment and Characterization of Airborne

9 Dust in Coal Surface Mine. BTech thesis.

10 [4] B. Fabiano, F. Curro, A.P. Reverberi, E. Palazzi. 2014. Coal dust emissions: From

11 environmental control to risk minimization by underground transport. An applicative case-study.

12 Process Safety and Environmental Protection. 92, 150-159.

13 [5] James G. Speight, CD\&W Inc., Laramie, WY, USA. 2016. Introduction to fuel flexible energy.

14 Fuel Flexible Energy Generation. 3-27.

15 [6] Panagiotis Grammelis, Nikolaos Margaritis, Emmanouil Karampinis. 2016. Solid fuel types

16 for energy generation: coal and fossil carbon-derivative solid fuels. Fuel Flexible Energy

17 Generation. 29-58.

18 [7] Chen, C. J. 2016. Technology Comparison of Closed Coal Yard Scheme. Journal of Anhui

19 Electrical Engineering Professional Technique College. 21(3), 86-91.

20 [8] Wang, J. Y. 2016. Monitor and Control System Research of Closed Coal Yard. Science \& 21 Technology Vision. 27, 405-405.

[9] Wang, C. X., Wang, Y. C. 2013. Design of A Closed House for Coal Separation. Inner Mongolia Environmental Sciences. 5, 77-79.

[10] S. Sumiyoshitani, T. Okada, M. Hara, M. Akazaki. 1984. Direct observation of the collection process for dust particles from an air stream by a charged water droplet. IEEE Transactions on Industry Applications. 20(2), 274-281.

[11] L.F. Gaunt, J.F. Hughes, N.M. Harrison. 2003. Removal of domestic airborne dust by naturally charged liquid sprays. Electrostat. 58, 159-169.

[12] M.A.E. Plinke, D. Leigh, M.G. Boundy, F. Loffler. 1995. Dust generation from handling powders in industry. Am. Ind. Hyg. Assoc. J. 56, 251-257.

[13] Zhilin Xi, Zhenya Feng, Ang Li. 2017. Synergistic coal dust control using aqueous solutions of thermoplastic powder and anionic surfactant. Colloids and Surfaces A: Physicochem. Eng. Aspects. 520, 864-871. [14] R. Susan Smandych, Murray Thomson, Howard Goodfellow. 1998. Dust Control for Material Handling Operations: A Systematic Approach. American Industrial Hygiene Association Journal.

37 [15] Xia, B., Liao, R., Grima, A., Pan, R. \& Wypych, P. 2016. Dust control technology for coal 38 handling and processing: Crushing station case study. ICBMH . 12, 73-82.

39 [16] Han Fangwei, Wang Deming, Jiang Jiaxing, Zhu Xiaolong. 2016. A new design of foam 40 spray nozzle used for precise dust control in underground coal mines. International 41 Journal of Mining Science and Technology.

42 [17] Gosia Stein-Brzozowska, Christian Bergins, Allan Kukoski, Song Wu, Michalis Agraniotis, 
1 Emmanouil Kakaras. 2016. The Current Trends in Conventional Power Plant Technology on Two

2 Continents From the Perspective of Engineering, Procurement, and Construction Contractor and

3 Original Equipment Manufacturer, Journal of Energy Resources Technology, 044501 / Vol. 138,

4 JULY 2016. 


\section{Declaration of interests}

$\bigotimes$ The author declares that he has no known competing financial interests or personal relationships that could have appeared to influence the work reported in this paper.

$\bigotimes$ The author declares that he has completed the research concept, analysis and manuscript preparation, data analysis and manuscript writing alone. This manuscript is not applicable for the follow section.

- Availability of data and materials

- Competing interests

- Funding

- Authors' contributions

- Acknowledgements

$\square$ The author declares the following financial interests/personal relationships which may be considered as potential competing interests: 
Figures

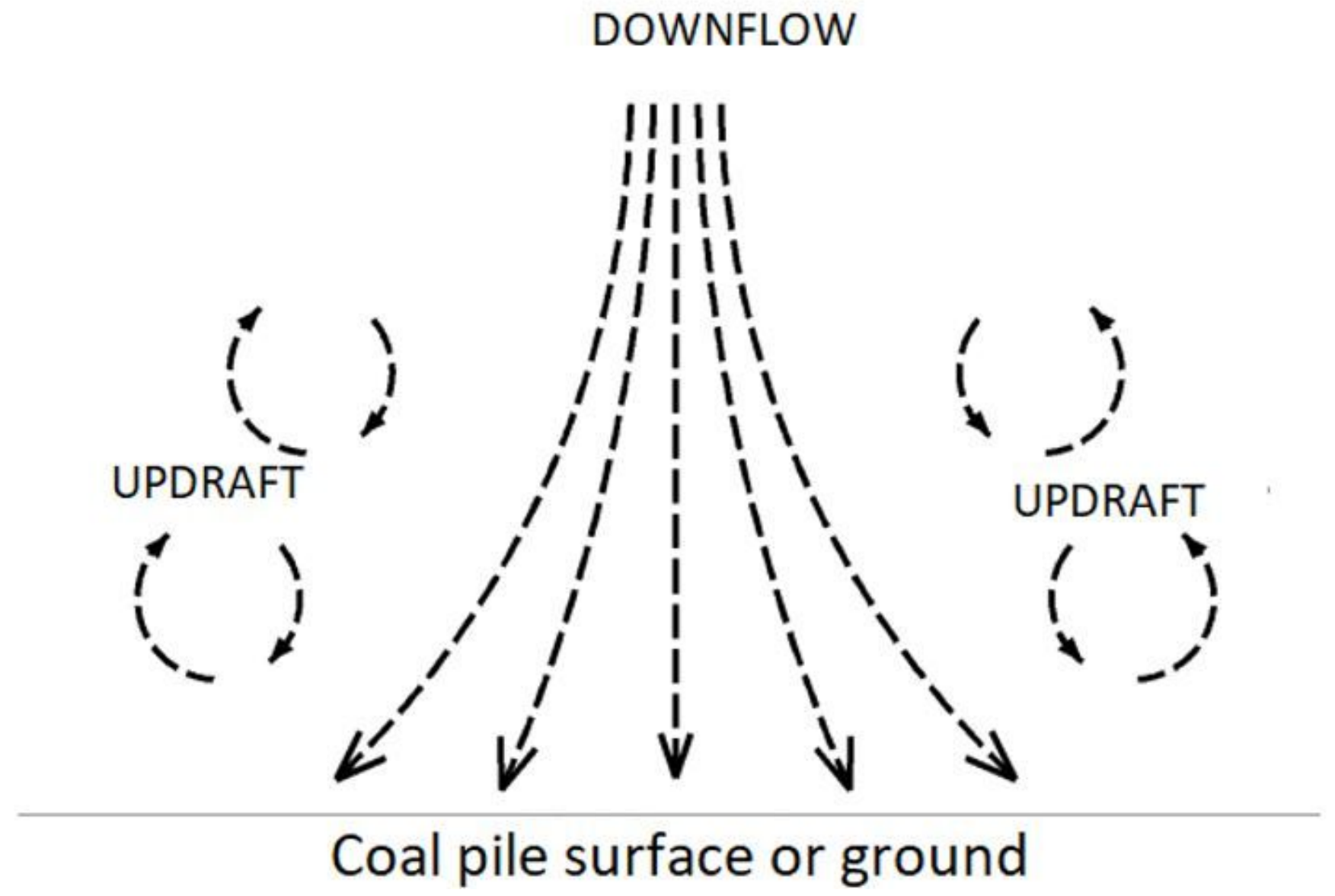

Figure 1

Airflow around falling Coal
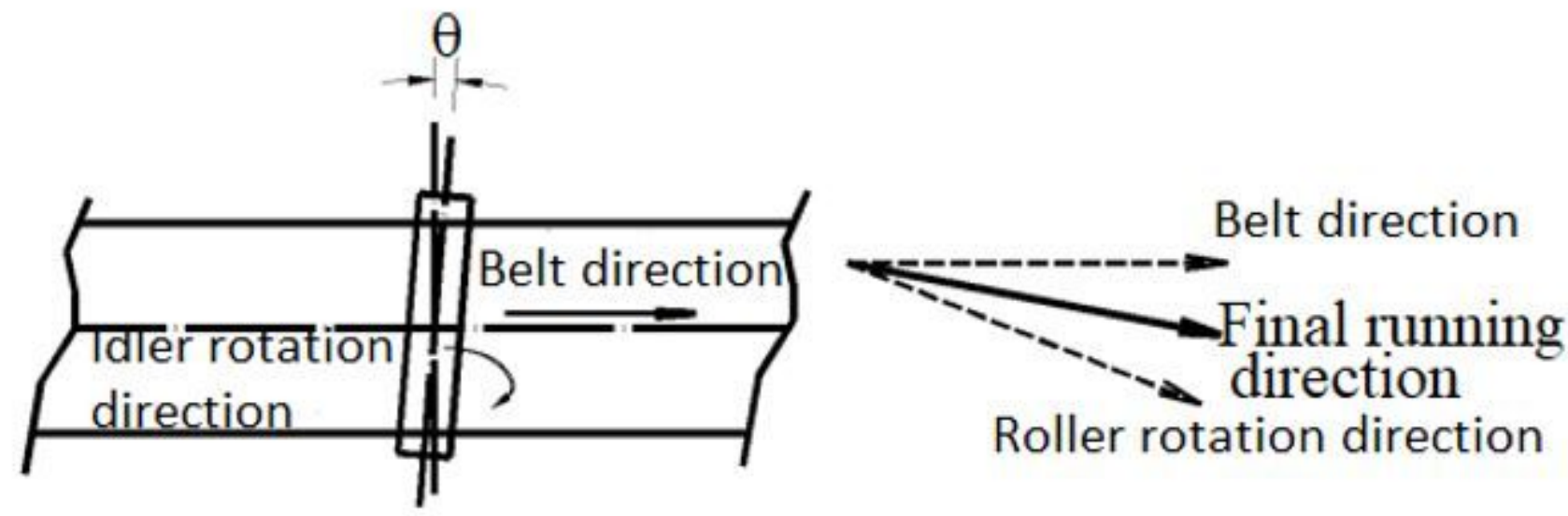

Figure 2

The idler is not perpendicular to the belt 


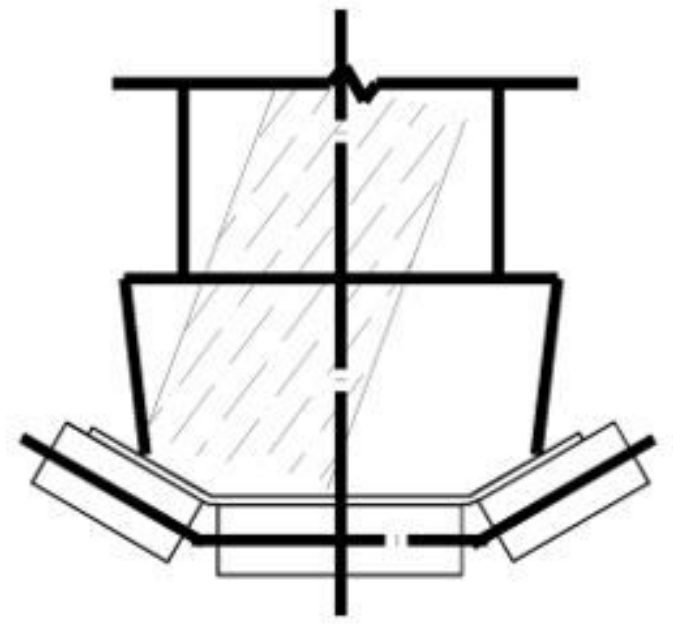

Figure 3

Blanking point eccentricity

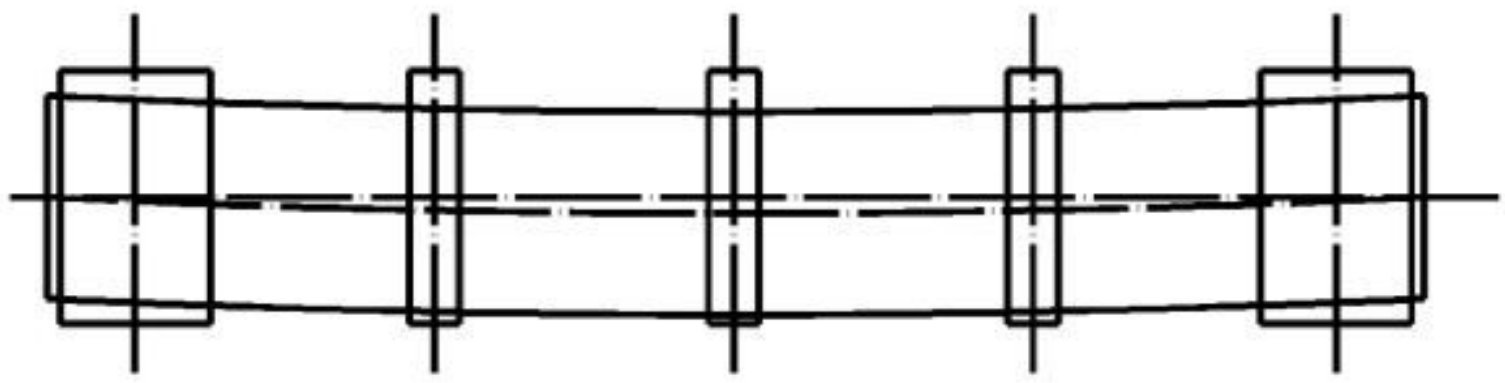

Figure 4

Bending centerline

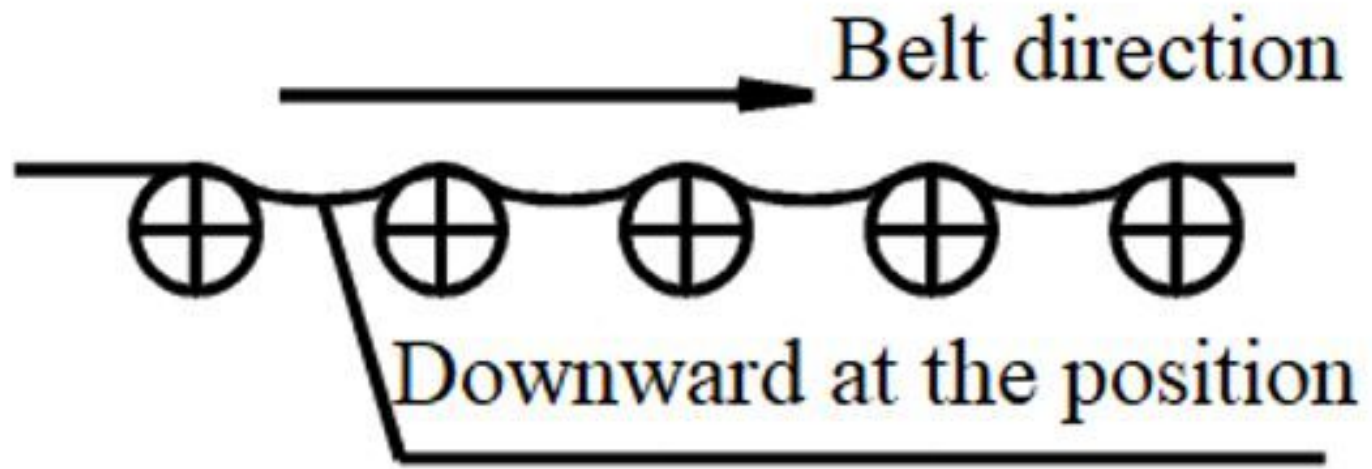

Figure 5 
The belt is in a subsidence state

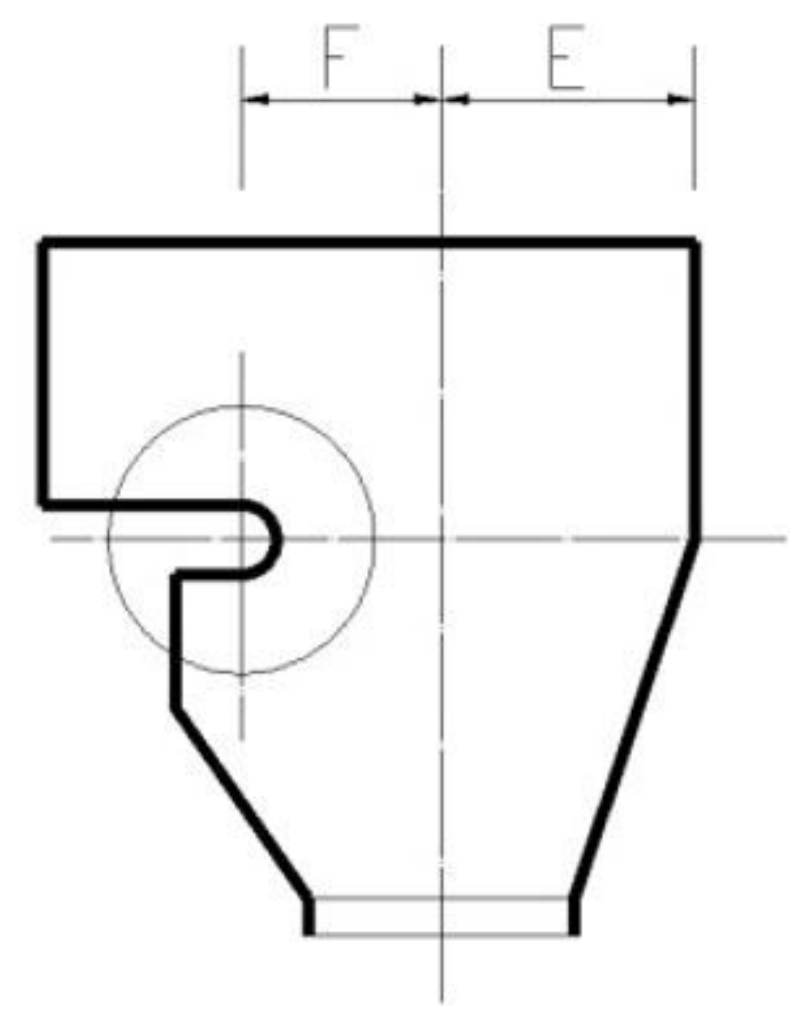

Figure 6

The head funnel of Conveyor 